\title{
Biological effects of the free and embedded metribuzin and tribenuron-methyl herbicides on various cultivated weed species
}

\author{
Tatiana Volova, Sergey Baranovsky, Olga Petrovskaya, Anna Shumilova, and Alexey Sukovatyi
}

\section{QUERY SHEET}

This page lists questions we have about your paper. The numbers displayed at left are hyperlinked to the location of the query in your paper.

The title and author names are listed on this sheet as they will be published, both on your paper and on the Table of Contents. Please review and ensure the information is correct and advise us if any changes need to be made. In addition, please review your paper as a whole for typographical and essential corrections.

Your PDF proof has been enabled so that you can comment on the proof directly using Adobe Acrobat. For further information on marking corrections using Acrobat, please visit http://journalauthors.tandf.co.uk/production/acrobat.asp; https://authorservices.taylorandfrancis.com/how-to-correct-proofs-with-adobe/

The CrossRef database (www.crossref.org/) has been used to validate the references.

\section{AUTHOR QUERIES}

Q1 Please provide the department/division name for both affiliations.

Q2 Please note that the ORCID section has been created from information supplied with your manuscript submission/CATS. Please correct if this is inaccurate. 


\section{Biological effects of the free and embedded metribuzin and tribenuron-methyl herbicides on various cultivated weed species}

${ }^{a}$ Siberian Federal University, Krasnoyarsk, Russia; ${ }^{b}$ Institute of Biophysics SB RAS, Federal Research Center "Krasnoyarsk Science Center SB RAS," Krasnoyarsk, Russia

Q1

\begin{abstract}
The present study addresses the herbicidal activity and biological effects of the metribuzin (MET) and tribenuron-methyl (TBM) herbicides used to control various weed species (Amaranthus retroflexus, Sinapis arvensis, and Leucanthemum maximum). The effects of the free herbicides and the herbicides embedded in granules of degradable polymer poly-3-hydroxybutyrate $[\mathrm{P}(3 \mathrm{HB})]$ blended with birch wood flour were compared. Metribuzin, regardless of the form, caused $100 \%$ mortality of the three weeds by day 21. The herbicidal activity of tribenuron-methyl was lower than that of metribuzin, but the embedded TBM was superior to the free herbicide in the length and strength of its action on the weeds. Both metribuzin forms dramatically decreased the main parameters of fluorescence: maximum quantum yield of photosystem-II [Y(II) max], maximum quantum yield of non-photochemical quenching $\left[\mathrm{Y}(\mathrm{NPQ})_{\max }\right]$, and maximum rate of non-cyclic electron transport $\left[\right.$ ETR $\left._{\max }\right]$ and concentrations of chlorophyll $a$ and $b$. The effect of the embedded TBM on the photosynthetic activity of the weeds was lower in the first two weeks of the growth of herbicidetreated plants but lasted longer than the effect of the free TBM and increased over time. Embedding of metribuzin in the matrix of degradable blend did not decrease its herbicidal activity.
\end{abstract}

\section{ARTICLE HISTORY}

Received 31 May 2020

Accepted 31 July 2020

\section{KEYWORDS}

Metribuzin; tribenuronmethyl; degradable $\mathrm{P}(3 \mathrm{HB})$; weed growth inhibition; photosynthetic activity

\section{Introduction}

Herbicide applications inevitably result in excessively high levels of chemicals in soil, posing health risks, causing some plant species to develop resistance to the herbicides applied, presenting threat to agroecosystems, disturbing their stability, and endangering long-term soil fertility. Because herbicides are used at enormous scale, playing a substantial part in agriculture, the development and application of new-generation environmentally safe herbicide formulations is a priority for agrochemists, biotechnologists, and horticulturists. A current research focus is to develop less toxic and more selective pesticides and reduce application rates.

Much research effort has been devoted recently to decreasing the risk of uncontrolled distribution and accumulation of pesticides in the biosphere by developing environmentally safe new-generation controlled release pesticide formulations in which the active ingredient is either coated by a layer or embedded in a matrix of a biodegradable material. The main condition for constructing such formulations is the availability of appropriate materials with the following properties:

1. compatibility with the environment and global biosphere cycles, i.e. degradability;

2. safety for living organisms and their nonliving environment;
3. long-term presence (for weeks and months) in the nat- 85 ural environment and controlled degradation followed 86 by formation of nontoxic products;

4. chemical compatibility with pesticides;

5. processability by available methods compatible with 89 processes of production of agrochemicals.

92

Materials investigated as candidates for constructing a 93 matrix for embedding pesticides include synthetic, non- 94 degradable polymers such as polystyrene, polyacrylamide, 95 polyethylene acrylate, polyamide, polyurethane, and polycya- 96 noacrylate. Studies published in recent years reported inves- 97 tigations of degradable materials that can be decomposed by 98 soil microflora without producing more contaminants, with 99 release of chemicals occurring gradually. These are such 100 materials as cellulose, agarose, dextran, carrageenan, starch, 101 chitosan, alginate, protein-containing gelatin, and albu- 102 min. ${ }^{[1]}$ The shortcomings of these natural polymers are their 103 low mechanical strength and rapid hydrolysis in liquid 104 media, which is an obstacle to preparing sustained-release 105 formulations of agrochemicals.

Among biodegradable materials, special attention is given 107 to biopolymers synthesized by microorganisms in biotechno- 108 logical processes such as polyhydroxyalkanoates (PHAs). 109 These polymers are thermoplastic, mechanically strong, and 110 slowly degradable in biological media. ${ }^{[2]}$ As these polymers 111 
decompose via truly biological degradation and do not undergo hydrolysis in liquid media, the products made from them may function, e.g. in soil, for months. The rates of release and delivery of the active ingredient can be varied within a wide range by controlling the degradation rate of the PHA matrix, by using products of different shapes that contain different amounts of preparations. The available literature data on using PHAs to construct environmentally safe pesticide formulations are limited. However, poly-3hydroxybutyrate $[\mathrm{P}(3 \mathrm{HB})]$ - the best studied and most commonly used PHA - has been successfully used to construct slow-release pesticide formulations. ${ }^{[2]}$ Metribuzin formulations were prepared in the form of films, microgranules, and microparticles based on $\mathrm{P}(3 \mathrm{HB}) .{ }^{[3]}$ Those formulations were found to be effective herbicides in experiments with weed model. ${ }^{[4]}$

They were also used to control weeds in the wheat stands. ${ }^{[5]}$ In order to make PHA polymers, whose cost is rather high now, more easily accessible and less expensive, research was conducted in which fungicides were embedded in matrices of degradable $\mathrm{P}(3 \mathrm{HB})$ blended with natural materials (peat, clay, and birch wood flour). ${ }^{[6,7]}$

One of the challenges in developing slow-release pesticide formulations is maintaining the biological efficacy of the active ingredient loaded into the matrix. Therefore, it is necessary not only to develop the process of constructing slow-release herbicide formulations but also to study their biological activity in weed control relative to the herbicidal activity of the free active ingredient. Plants affected by herbicides and suffering photosynthetic stress should be investigated to estimate the state of their photosynthetic apparatus, chlorophyll fluorescence parameters, and the content of chlorophyll-protein complexes. Herbicides were found to slow down photosynthesis rate, decrease the contents of green pigments and carotenoids, inhibit $\mathrm{CO}_{2}$ assimilation, and impair plant nutrition and growth. ${ }^{[8]}$

These damages are caused not only by herbicides aimed at photosynthesis (atrazine, metribuzin, etc.), ${ }^{[9]}$ but also, as reported in recent studies. ${ }^{[10]}$ By such herbicides as glyphosate and imazethapyr, whose main targets are acetolactate synthase and reactions of synthesis of branched-chain amino acids.

The purpose of the present study was to investigate the biological efficacy of the slow-release metribuzin and tribenuron-methyl herbicides loaded into the matrix of degradable poly-3-hydroxybutyrate blended with birch wood flour in controlling different weed species, taking into account weed mortality dynamics and inhibition of photosynthetic activity.

\section{Materials and methods}

\section{Herbicides}

Two herbicides with different modes of action were studied: metribuzin (MET) and tribenuron-methyl (TBM).

Metribuzin [4-amino-6-tert-butyl-3-methylthio-1,2,4-triazin-5 $(4 \mathrm{H})$-one] is a systemic selective herbicide of the class of 1,2,4-triazines, having a broad spectrum activity against some dicots and grass weeds. MET has a long-lasting effect, acting via both leaves and soil. The mode of action is based on inhibiting the Hill reaction (water photolysis) and photosynthetic electron transport between primary and secondary electron acceptors in Photosystem II. MET effectively protects soybean, maize, cereal, potato, and tomato crops from annual dicots and grass weeds.

Tribenuron-methyl [methyl ester of 2-(6-methyl-4methoxy-1,3,5-triazin-2-yl(methyl) carbamoylsulfamoyl) benzoic acid] is a systemic selective herbicide of the sulfonylurea family. The mode of action is based on inhibiting acetolactate synthase, which takes part in biosynthesis of branched-chain amino acids (valine, leucine, and isoleucine), causing a decrease in the levels of these amino acids in plant tissues followed by disruption of protein and nucleic acid synthesis. TBM effectively protects cereal crops from dicots and grass weeds.

The metribuzin and tribenuron-methyl herbicides used in experiments with plants were supplied by Xi'anTai Cheng Chem Co., Ltd (China); the content of the active ingredient in metribuzin was $97.2 \%$ and in tribenuron-methyl - 95.5\%

\section{Materials for embedding herbicides}

$\mathrm{P}(3 \mathrm{HB})$ polymer samples were synthesized using the Cupriavidus eutrophus B10646 strain and proprietary technology. ${ }^{[2]}$ Polymer was extracted from cells with chloroform, and the extracts were precipitated using hexane. The extracted polymers were re-dissolved and precipitated again 3-4 times to prepare homogeneous specimens. The polymer had the following properties: degree of crystallinity $75 \%$, melting point $176^{\circ} \mathrm{C}$, thermal decomposition temperature $287^{\circ} \mathrm{C}$, molecular weight $\left(\mathrm{M}_{\mathrm{w}}\right) 590 \mathrm{kDa}$, and polydispersity index 5.8 .

A natural material, wood flour, was used as filler. Wood flour was produced by grinding wood of birch (Betula pendula Roth) using an MD 250-85 woodworking machine ("StankoPremyer" Russia). Then it was dried at $60^{\circ} \mathrm{C}$ for $120 \mathrm{~h}$ until it reached constant weight, and $0.5 \mathrm{~mm}$ mesh was used to separate the particle size fraction; degree of crystallinity $26 \%$; onset of thermal decomposition $220^{\circ} \mathrm{C}$.

\section{Experimental herbicide formulations}

The polymer and wood flour were pulverized by impact and shearing action in ultra-centrifugal mill ZM 200 (Retsch, Germany). To achieve high fineness of polymer grinding, the material and the mill housing with the grinding tools were preliminarily cooled at $-80^{\circ} \mathrm{C}$ for about $30 \mathrm{~min}$ in an Innova U101 freezer (NEW BRUNSWICK SCIENTIFIC, U.S.). Grinding was performed using a sieve with $2-\mathrm{mm}$ holes at a rotor speed of $18000 \mathrm{rpm}$. The fractional composition of the polymer and filler powders was determined using vibratory sieve shaker AS 200 control (Retsch, Germany). Then, polymer powder was mixed with the filler powder in benchtop planetary mixer SpeedMixer DAC 250 SP (Hauschild Eng., Germany); the blend time was $1 \mathrm{~min}$, and the speed was $1000 \mathrm{rpm}$. 
Table 1. Chemical characterization of soil $(0-20 \mathrm{~cm})$.

\begin{tabular}{lc}
\hline Parameter & Value \\
\hline $\mathrm{pH}_{\mathrm{H} 2 \mathrm{O}}$ & 7.2 \\
Humus, \% & 10.7 \\
Hydrolytic acidity, mmol/100 g & 0.75 \\
Total absorbed bases, $\mathrm{mmol} / 100 \mathrm{~g}$ & 71.0 \\
Cation exchange capacity, $\mathrm{mmol} / 100 \mathrm{~g}$ & 71.8 \\
Base saturation, \% & 99.0 \\
Nitrate nitrogen, $\mathrm{mg} / \mathrm{kg}$ & 16.0 \\
Ammonium nitrogen, $\mathrm{mg} / \mathrm{kg}$ & 10.1 \\
Labile phosphorus, $\mathrm{mg} / \mathrm{kg}$ & 239.0 \\
Exchangeable potassium, $\mathrm{mg} / \mathrm{kg}$ & 110.7 \\
Exchangeable calcium, $\mathrm{mmol} / 100 \mathrm{~g}$ & 27.2 \\
Exchangeable magnesium, $\mathrm{mmol} / 100 \mathrm{~g}$ & 4.3 \\
Silt and clay content, \% & $64-65$ \\
$\quad$ Including: sand, $\%$ & $35-36$ \\
Silt fraction, \% & $36-39$ \\
\hline
\end{tabular}

Herbicide granules were prepared using polymer paste wetted with ethanol and mixed with birch wood flour and the herbicide in screw granulator Fimar (Italy). The formulations contained the following percentages of the components: $\mathrm{P}(3 \mathrm{HB}) /$ wood flour/herbicide - 50/30/20 (wt.\%). The solid granules were $3 \mathrm{~mm}$ in diameter and 4 to $6 \mathrm{~mm}$ long. In the positive control, herbicides were applied to the soil as solutions at concentrations equal to the concentrations applied with granules.

\section{Weeds}

The following plant species were used as weeds: red-root amaranth (Amaranthus retroflexus) - a widespread annual spring herb, infesting tilled crops and grain crops (wheat, rye, oat, barley, and corn) and occurring in kitchen gardens; field mustard (Sinapis arvensis) - an annual plant, heavily infesting spring grain fields; max chrysanthemum (Leucanthemum maximum) - a perennial taproot herb, growing $80 \mathrm{~cm}$ tall, infesting perennial grasses and various annual crops, mainly grain crops.

Metribuzin is a broad-spectrum herbicide, effective against red-root amaranth and field mustard. Tribenuronmethyl suppresses broadleaf weeds, including various mustard varieties.

\section{Cultivation and evaluation of parameters of weeds affected by herbicides}

Weeds were grown in laboratory soil microecosystems in a 35-day experiment. The soil was collected at the field laboratory of Krasnoyarsk State Agrarian University, in the vicinity of Krasnoyarsk (Russia). It was meadow-chernozem soil, whose soil profile was similar to the profile of chernozem soils with a thick humus-rich layer and loose granular structure. The soil was neutral, with low hydrolytic activity and high contents of nitrogen, labile phosphorus, and exchangeable potassium (Table 1).

The soil was collected from a plot that had not been treated with pesticides, including metribuzin and tribenuron-methyl. The seeds for the experiments were taken from the collection of the Department of Terrestrial Ecosystems of the Siberian Federal University. Seeds had been collected in the vicinity of the city of Krasnoyarsk, in a 292 natural forest (mixed birch-pine forest), $20 \mathrm{~km}$ away from 293 the city. This area has never been used as agricultural land 294 and no pesticides have been used there. Agricultural land is 295 $30-40 \mathrm{~km}$ away from the seed collection site. Thus, the 296 plants grown in the experimental systems could not have 297 developed resistance to these herbicides, and the effect of 298 the herbicides was their true biological effect.

Soil was placed into $500-\mathrm{cm}^{3}$ plastic containers ( $400 \mathrm{~g}$ soil 300 per container), and plant seeds were sown in the soil (150 $\mathrm{g} 301$ seeds per $1 \mathrm{~m}^{2}$ ). Granules with embedded herbicides were 302 placed in close-meshed gauze bags and buried in the soil at 303 a depth of $1.5-2.0 \mathrm{~cm}$ simultaneously with sowing. The 304 application rates of MET and TBM corresponded to the rec- 305 ommended application rates of these herbicides: $400 \mathrm{~g} / \mathrm{ha} 306$ and $20 \mathrm{~g} / \mathrm{ha}$, respectively. ${ }^{[11]}$ In the positive control, solu- 307 tions of unembedded herbicides were added to soil at rates 308 recommended for field application and corresponding to 309 herbicide concentrations in granules. The herbicides were 310 preliminarily dissolved in distilled water at room tempera- 311 ture on a shaker until complete dissolution was achieved, 312 and $100 \mathrm{ml}$ of the solution was added to the soil in each 313 container before seed sowing. The target concentrations of 314 herbicides embedded in the matrix were achieved by varying 315 the amounts of the granules buried in the soil. Plants were 316 grown in an environmental chamber (Fitotron-LiA-2, 317 Russia). The temperature, lighting, and soil moisture content 318 were controlled in the six-step mode: "night - early morning 319 - late morning - early afternoon - late afternoon - eve- 320 ning". The temperature was varied between $10^{\circ} \mathrm{C}$ by night 321 and $18^{\circ} \mathrm{C}$ by day in the first seven weeks of the experiment 322 and between $14{ }^{\circ} \mathrm{C}$ by night and $22^{\circ} \mathrm{C}$ by day in the follow- 323 ing five weeks. Lighting was varied between 0 and $300 \mu \mathrm{mol} / 324$ $\mathrm{m}^{2} / \mathrm{s}$, in $100 \mu \mathrm{mol} / \mathrm{m}^{2} / \mathrm{s}$ increments. The lowest soil moisture 325 content was $50 \%$.

Samples for analysis were collected weekly. Other indica- 327 tors of the state of the weeds were the time when the high- 328 est mortality rate was achieved and plant density (the 329 number of plants per $1 \mathrm{~m}^{2}$ ). Weed plant mortality was 330 monitored by counting the number of the dead and living 331 weed plants in a container. At each time point, plants in 332 three containers were counted in each experiment. To study 333 photosynthesis reactions and determine pigments, three 334 leaves per plant were collected from at least three plants 336 per container.

Biological efficacy of the embedded herbicides was esti- 337 mated using corrected percent mortality, $\mathrm{C}_{\text {cor }}$, derived from 338 modified Abbot's formula, ${ }^{[12]}$ which shows the decrease in 339 the number of weeds caused by application of herbicides 341 (percent of the initial infestation or the control) corrected 342 for the control:

$$
C_{c o r}=100-\frac{\frac{B_{0}}{A_{0}} * a_{k}}{b_{k}} * 100
$$

where:

$\mathrm{A}_{0}$ is the number of weed plants per $\mathrm{m}^{2}$ to determine the 348 initial infestation rate in the treatment;

$\mathrm{B}_{0}$ - the same in the second and following counts; 

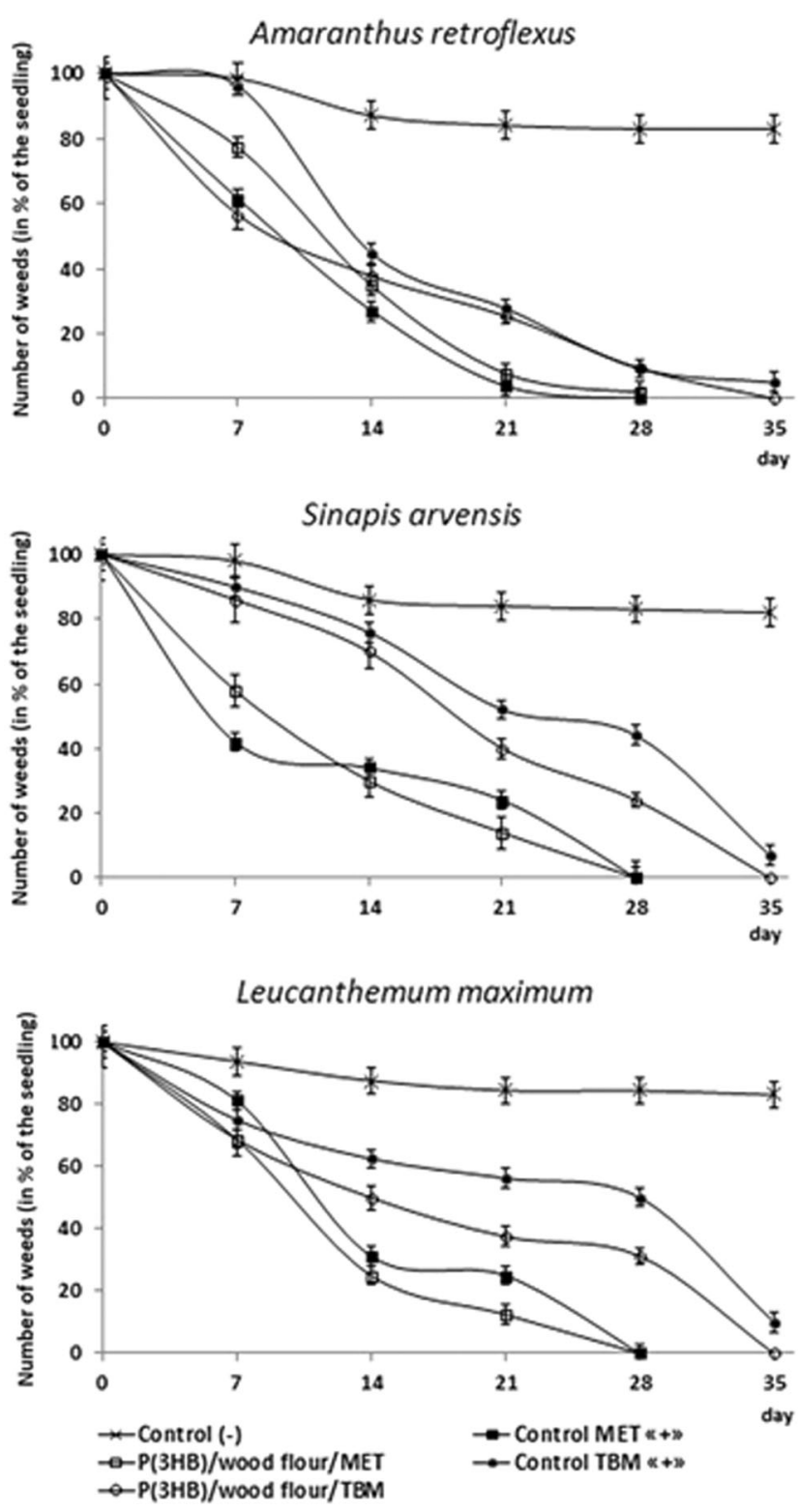

Figure 1 . Weed mortality dynamics (weeds as \% of seedlings): Amaranthus retroflexus, Sinapis arvensis, Leucanthemum maximum. Negative control (intact plants without herbicide treatment); positive control (free metribuzin and tribenuron-methyl); embedded herbicides: $\mathrm{P}(3 \mathrm{HB}) /$ wood flour/MET and $\mathrm{P}(3 \mathrm{HB}) /$ wood flour/TBM.

$a_{k}$ - the number of weed plants per $\mathrm{m}^{2}$ to determine the initial infestation rate in the control;

$b_{k}$ - the same in the second and following counts.

\section{Study of the effect of herbicides on plant photosynthesis parameters}

The effect of herbicides on the photosynthetic activity of plants was studied using leaves of the weeds: rapid chlorophyll fluorescence was measured employing pulse amplitude modulated fluorometers (PAM) (Walz, Effeltrich, Germany). Before measurements, the leaves were dark adapted for $30 \mathrm{~min}$. Actinic light intensity was increased stepwise $(0,66$, $90,125,190,285,420,625$, and $820 \times 10^{-6} \mathrm{M}$ photo$\mathrm{ns} \cdot \mathrm{m}^{-2} \cdot \mathrm{s}^{-1}$ ) at $10 \mathrm{~s}$ intervals. Fluorescence parameters were measured at ambient temperature and humidity. The following fluorescence parameters were measured: $\mathrm{Y}(\mathrm{II})_{\max }$ - maximum quantum yield of Photosystem-II (PSII); Y(NPQ) $\max -\max -$ imum quantum yield of non-photochemical quenching; $\mathrm{ETR}_{\max }$ - maximum rate of non-cyclic electron transport.

\section{Quantification of chlorophyll-protein complexes}

To extract pigments of photosynthesis from fresh plant material, a 40-60 mg leaf sample (without midrib) was placed into a $15-\mathrm{ml}$ test tube. Five $\mathrm{ml} 95 \%$ ethyl alcohol and $10 \mathrm{mg} \mathrm{CaCO}_{3}$ powder were added, and the test tube was plugged with a PE foam stopper. Pigments were extracted in water bath at a temperature of $60^{\circ} \mathrm{C}$ until the leaf was completely bleached (usually for 20-30 min). Then, the test tubes were placed into a refrigerator for $12 \mathrm{~h}\left(+4{ }^{\circ} \mathrm{C}\right)$ and left in the dark until pigment extraction was completed and solution clarified. Pigments were quantified by spectrophotometry. Optical density was measured using a Specol-1300 spectrophotometer (Germany). Concentrations of $\mathrm{C}_{\mathrm{a}}$ and $\mathrm{C}_{\mathrm{b}}$ chlorophylls and total xanthophylls and carotenes $\mathrm{C}_{\mathrm{x}+\mathrm{c}}(\mu \mathrm{g} / \mathrm{ml})$ were calculated using conventional formulas. ${ }^{[13]}$ Pigment contents were expressed as $\mathrm{mg} \times \mathrm{g}^{-1}$ fresh mass.

\section{Statistical analysis}

Results were expressed as the average from three parallel experiments performed with triplicates and presented as the mean \pm SE. Statistical comparisons of the means between each treatment and the control were performed using analysis of variance. Statistical probability $(P)$ was set at 0.05 .

\section{Results and discussion}

\section{The effect of herbicides on weed mortality dynamics}

Experimental formulations of both MET and TBM showed herbicidal activity toward the weeds comparable or even superior to the herbicidal activity of free MET and TBM (Fig. 1).

The experiment with red-root amaranth, field mustard, and max chrysanthemum showed that both herbicides inhibited the growth of the three weeds. The herbicidal activity was detected at day 7 , and metribuzin was more effective than tribenuron-methyl. The highest mortality rate of the weeds was achieved earlier in the MET treatment than in the TBM treatment (at day 14), when the abundance of plants treated with MET was no more than $25 \%-30 \%$ of the initial abundance; at day 28 , all plants died.

A search of the literature on the efficacy of metribuzin revealed that research mainly focused on biological effects of different concentrations of this herbicide on various weed species, but no comparison was made between the efficacy and properties of the free and embedded herbicide. Metribuzin is effective against various broadleaf weeds and grasses, and traditional pre-emergence soil applications of this herbicide in potato fields proved that it effectively 


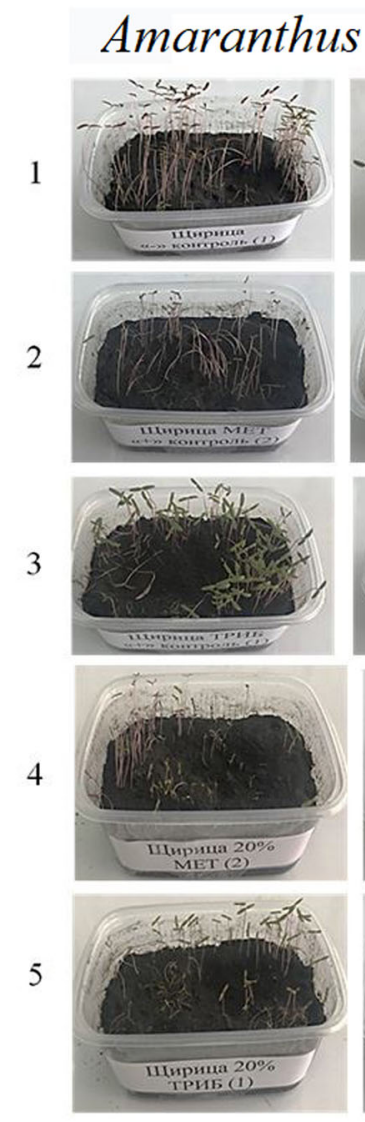

14
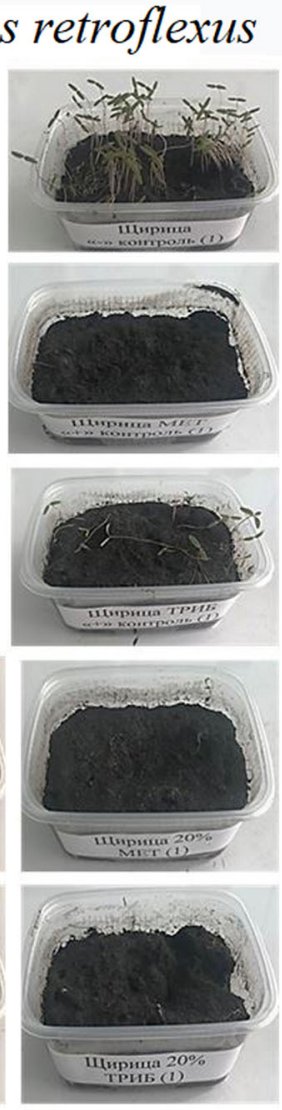

28

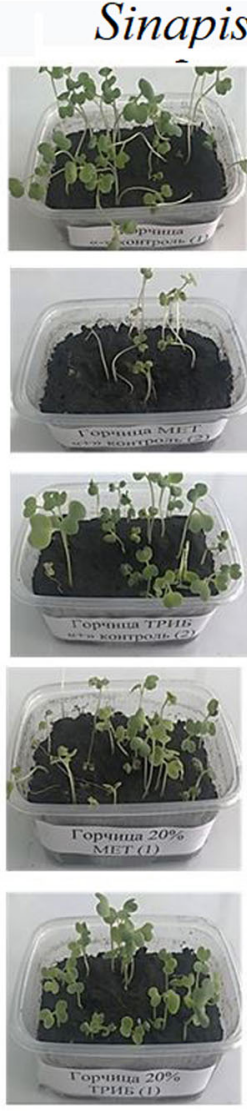

14
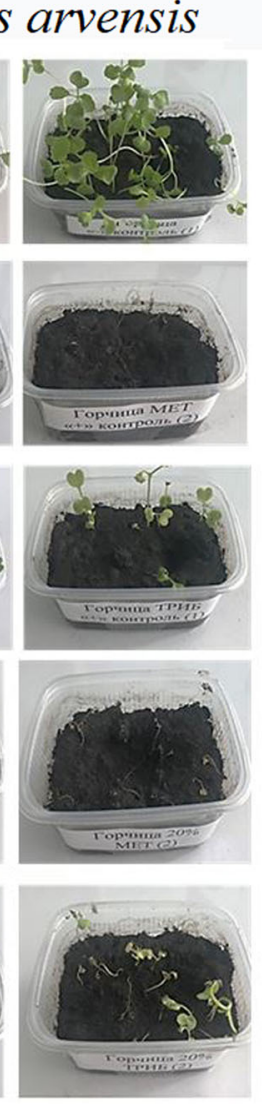

28
Leucanthemum maximum
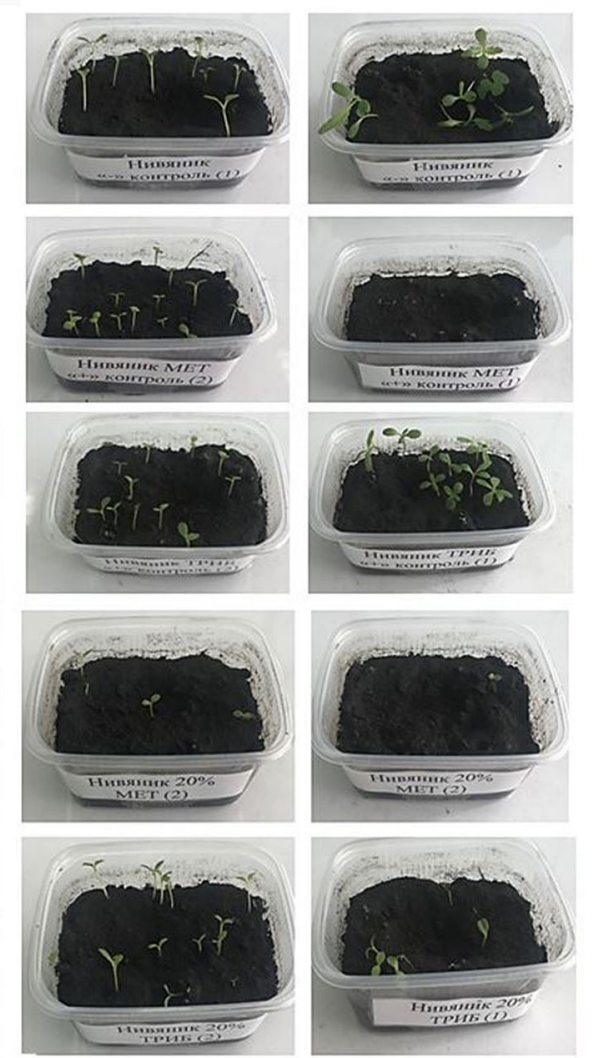

14

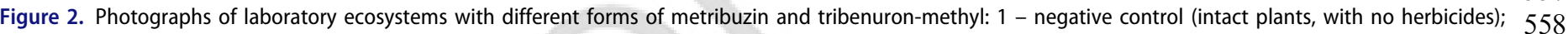

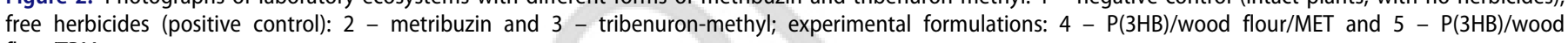
flour/TBM.

controlled Amaranthus retroflexus and Chenopodium album without reducing potato yield. ${ }^{[14]}$ The effects of different metribuzin doses (105 to $525 \mathrm{~g} / \mathrm{ha}$ ) on red-root amaranth (Amaranthus retroflexus L.) and field mustard (Sinapis arvensis L.) were investigated in this study, showing that the biomass of red-root amaranth was reduced by $90 \%$ when MET was applied at the BBCH $12-15$ and $\mathrm{BBCH} 16-19$ growth stages, respectively, at a concentration of $525 \mathrm{~g} / \mathrm{ha}$. The decrease in the biomass of $S$. arvensis in the same growth stages, BBCH $12-15$ and $\mathrm{BBCH} 16-19$, occurred at lower metribuzin concentrations $(263 \mathrm{~g} / \mathrm{ha})$. Metribuzin was used in maize fields to test its efficacy against the Portulaca oleracea, Amaranthus retroflexus, and Echinochloa colonum weeds, and the biomass of the weeds was reduced by $97.7 \%$, $96.9 \%$, and $97.2 \%$, respectively. ${ }^{[15]}$ These results were consistent with the data reported by Medd et al., ${ }^{[16]}$ suggesting that herbicide efficacy varied depending on the weed species. In addition, weeds at the $\mathrm{BBCH} 12-15$ growth stage were found to be more sensitive to the effects of herbicides. This finding is consistent with the conclusion made by Riethmuller-Haage et al., ${ }^{[17]}$ suggesting that the metribuzin dose necessary to control weeds varied depending on the leaf area and number of leaves and that the effect of herbicides became weaker as the plants were growing. A few studies addressed the relationship between the herbicidal activity and the form of herbicide delivery. Experiments with polycaprolactone nanocapsules with the atrazine herbicide, whose mode of action is similar to that of metribuzin - inhibition of plant photosynthesis, showed higher efficacy of encapsulated atrazine compared to the free herbicide used for post-emergence treatment of Amaranthus viridis and Bidens pilosa. ${ }^{[18]}$

Experiments with tribenuron-methyl showed that, regard- 568 less of its form, its herbicidal action toward field mustard 569 and max chrysanthemum was weaker than the effect of 570 MET (Fig 1). Only the mortality rate of red-root amaranth 571 572 reached its peak at the same dates as in the MET experi- 573 ment. The highest mortality rates of the other weed species 573 (field mustard and max chrysanthemum) were achieved 574 later. At day 21, the abundances of both weed species were 576 reduced to $50 \%-60 \%$; a week later (day 28), weed mortality 577 did not reach $100 \%$, in contrast to the MET treatments. The 578 abundance of the remaining weed plants was rather high, 579 between $25 \%-35 \%$ and $40 \%-50 \%$. A significant difference 580 was noted between the herbicidal activities of the embedded 581 TBM and the unembedded herbicide. The embedded TBM 582 was more effective, killing all weed plants by day 35 . At the 583 same time point, in the ecosystems with the free TBM, 584 $5 \%-10 \%$ field mustard and max chrysanthemum plants still 585 remained alive. 
Table 2. Biological efficacy $\left(\mathrm{C}_{\text {cor }}\right)$ of the $\mathrm{P}(3 \mathrm{HB})$ /wood flour/MET and $\mathrm{P}(3 \mathrm{HB}) /$ wood flour/TBM experimental formulations compared to the efficacy of free metribuzin and tribenuron-methyl.

\begin{tabular}{lccc}
\hline & \multicolumn{3}{c}{ Biological efficacy $C_{\text {cor }}(\%)$} \\
\cline { 2 - 4 } Treatment/control & 14 day & 21 day & 28 day \\
\hline Amaranthus retroflexus & & & \\
Control MET (400 g/ha) «+» & $66.7 \pm 5.2$ & $95.0 \pm 4.2$ & 100.0 \\
Control TBM (20 g/ha) «+» & $44.8 \pm 3.6$ & $64.0 \pm 4.0$ & $88.0 \pm 4.2$ \\
P(3HB)/wood flour/MET & $57.1 \pm 4.3$ & $90.0 \pm 3.7$ & $97.5 \pm 2.1$ \\
P(3HB)/wood flour/TBM & $53.3 \pm 4.7$ & $67.0 \pm 5.4$ & $92.0 \pm 3.4$ \\
Sinapis arvensis & & & \\
Control MET (400 g/ha) «+» & $60.5 \pm 5.0$ & $71.4 \pm 3.3$ & 100.0 \\
Control TBM (20 g/ha)«+» & $11.6 \pm 1.2$ & $38.1 \pm 2.6$ & $45.0 \pm 2.1$ \\
P(3HB)/wood flour/MET & $65.1 \pm 5.6$ & $83.3 \pm 4.0$ & 100.0 \\
P(3HB)/wood flour/TBM & $18.6 \pm 1.8$ & $52.4 \pm 3.7$ & $70.0 \pm 3.4$ \\
Leucanthemum maximum & & & \\
Control MET (400 g/ha) «+» & $64.3 \pm 5.3$ & $70.4 \pm 3.8$ & 100.0 \\
Control TBM (20 g/ha) «+» & $28.6 \pm 1.7$ & $33.3 \pm 2.2$ & $40.7 \pm 2.5$ \\
P(3HB)/wood flour/MET & $71.4 \pm 5.9$ & $85.2 \pm 3.0$ & 100.0 \\
P(3HB)/wood flour/TBM & $42.9 \pm 3.8$ & $55.6 \pm 3.3$ & $63.0 \pm 3.9$ \\
\hline
\end{tabular}

The latest literature data suggest that the effect of tribenuron-methyl, like the effect of metribuzin, varies depending on the target weed species and the time and rate of herbicide application. Gherekhloo et al. ${ }^{[19]}$ described the dosedependent effect of TBM on different generations of Sinapis arvensis and showed that as plants became more resistant, the standard dose of TBM (15 g/ha) needed to be increased by $2.2-16.8$ times. Similar results were obtained in another study of TBM effect on Sinapis arvensis. ${ }^{[20]}$ TBM was found to be less effective in weed control than triazine and chlorotriazine herbicides. ${ }^{[21]}$ However, the ability of embedded or free sulfonylurea herbicides to inhibit growth and development of various weeds was confirmed in a number of studies, ${ }^{[22]}$ including studies performed with such weeds as Amaranthus tuberculatus, Amaranthus palmeri, and Amaranthus spp. ${ }^{[23]}$

\section{Biological efficacy of embedded herbicides}

The herbicidal efficacy of different forms of herbicides and the dissimilarities between the effects of MET and TBM and their embedded and unembedded forms are clearly seen in the photographs of the weed stands taken at different time points of the experiment (Fig. 2). In the MET treatments, no weeds can be seen at the end of the experiment while in the TBM treatments, some of the field mustard and max chrysanthemum plants remained alive, and their abundances were different in the ecosystems with the free and embedded TBM.

Results are summarized in Table 2, which shows the dynamics of biological efficacy determined for the experimental formulations of metribuzin [P(3HB)/wood flour/ $\mathrm{MET}]$ and tribenuron-methyl $[\mathrm{P}(3 \mathrm{HB}) /$ wood flour/TBM] compared to the effects of the free herbicides and relative to the abundance of weed plants in the negative control. At day 28, the biological efficacy of the embedded MET was $100 \%$ in the red-root amaranth, field mustard, and max chrysanthemum stands. The biological efficacy of the embedded TBM was generally somewhat lower than the efficacy of the embedded MET: $97.1 \%$ for red-root amaranth,
$70 \%$ for field mustard, and $63 \%$ for max chrysanthemum at day 28. The herbicidal activity of free TBM was inferior to that of the experimental formulations, and at day 28 , the biological efficacy of free TBM was $88.0 \%$ for red-root amaranth and slightly above $40 \%$ for field mustard and max chrysanthemum. The somewhat lower herbicidal activity of TBM may be associated with the well-known ability of this herbicide to be metabolized in higher plant tissues to yield compounds that are not toxic to plants. Thus, it is very important to be able to prolong and enhance its effects by loading it into a degradable matrix.

Experiments showed that embedding of the herbicides enhanced their activity toward the weeds rather than decreased it.

\section{Functional activity of the photosynthetic apparatus of weeds affected by herbicides}

The study of the effect of the free and embedded metribuzin on chlorophyll fluorescence parameters in different weed species showed that both MET forms considerably inhibited the photosynthetic apparatus of the three weed species compared to the negative control (Fig. 3). At day 14, the values of the fluorescence parameters (Y(II) $)_{\max }$ and $\mathrm{ETR}_{\max }$ ) in different species dropped by a factor of 2 to 8 relative to the negative control. Then, both parameters continued declining, and at day 21, they reached almost zero level. The reason for such dramatic inhibition of plant photosynthetic activity by metribuzin is the well-known negative effect of this herbicide on photosynthesis reactions. ${ }^{[10,24]}$

The decrease in the photosynthesis parameters, $\mathrm{Y}(\mathrm{II})_{\max }$ and $\mathrm{ETR}_{\max }$, of the weeds affected by MET may be directly related to the increase in concentration of hydrogen peroxide, which is a strong inhibitor of photosynthesis: even low $\mathrm{H}_{2} \mathrm{O}_{2}$ concentrations inhibit $\mathrm{CO}_{2}$ fixation by oxidizing thiol groups of some enzymes in the Calvin cycle. ${ }^{[25]}$ The decrease in ETR may be associated with the decrease in the ascorbate pool, which in turn impairs antioxidant protection of cells. ${ }^{[10]}$

The maximum quantum yield of non-photochemical quenching, $\mathrm{Y}(\mathrm{NPQ})_{\max }$, in the plants decreased insignificantly at day 14, approaching zero at day 21 , similar to parameters $\mathrm{Y}(\mathrm{II})_{\max }$ and $\mathrm{ETR}_{\max }$ (Fig. 3). NPQ is directly or indirectly related to light harvesting by photosynthetic antenna complexes, their structure, transfer of the captured energy to reaction centers, electron transport, proton transport across the membrane, ATPase activity, and carbon assimilation. ${ }^{[26-28]}$ Thus, metribuzin, regardless of its delivery form, interrupted the key processes of photochemistry in the weeds, as evidenced by the dynamics of parameters of photosynthetic activity $-\mathrm{Y}(\mathrm{II})_{\max }, \mathrm{ETR}_{\max }$, and $\mathrm{Y}(\mathrm{NPQ})_{\max }$. A similar decrease in the photosynthesis variables was observed in the experiments with MET-treated wheat plants. ${ }^{[8]}$ Qien et al. ${ }^{[29]}$ reported the effects of sublethal doses of atrazine (Atr) and methyl viologen (MV) on the photosynthetic electron transport in Arabidopsis thaliana. Four herbicides (paraquat, norflurazon, flazasulfuron, and atrazine) used in experiment with Lemna minor inhibited 

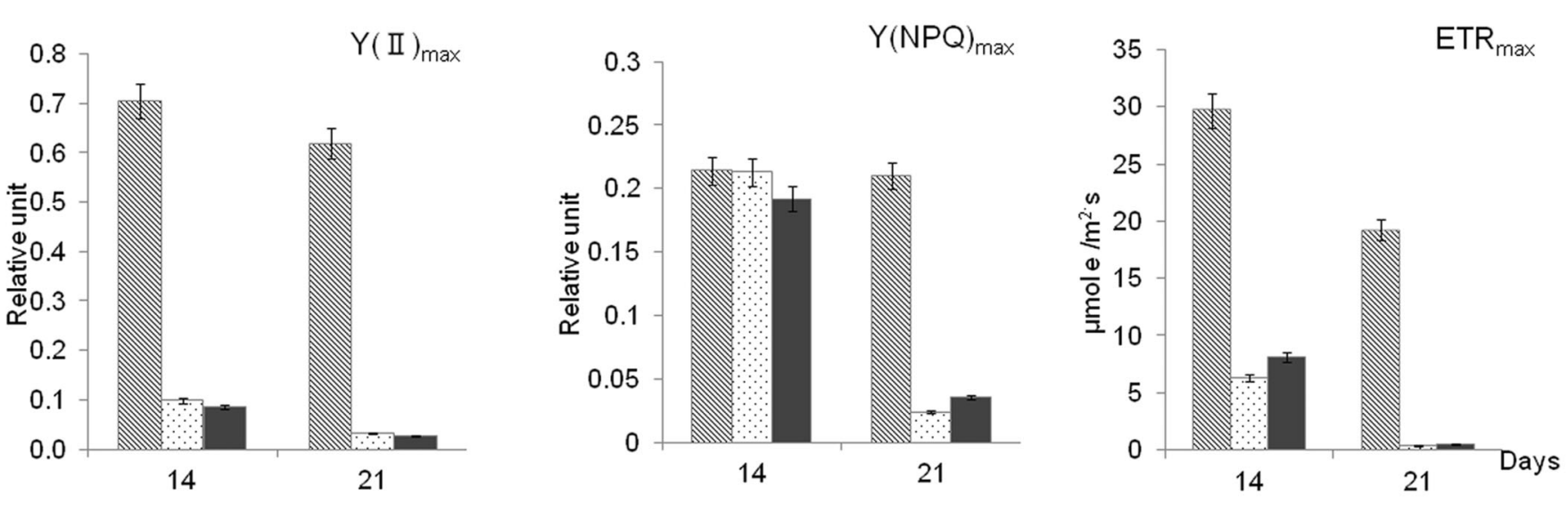

765

708

709

710

711

712

713

714

715

716

717

718

719

720

721

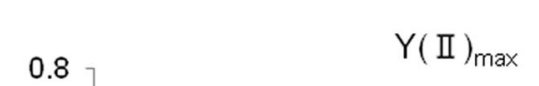

Amaranthus retroflexus
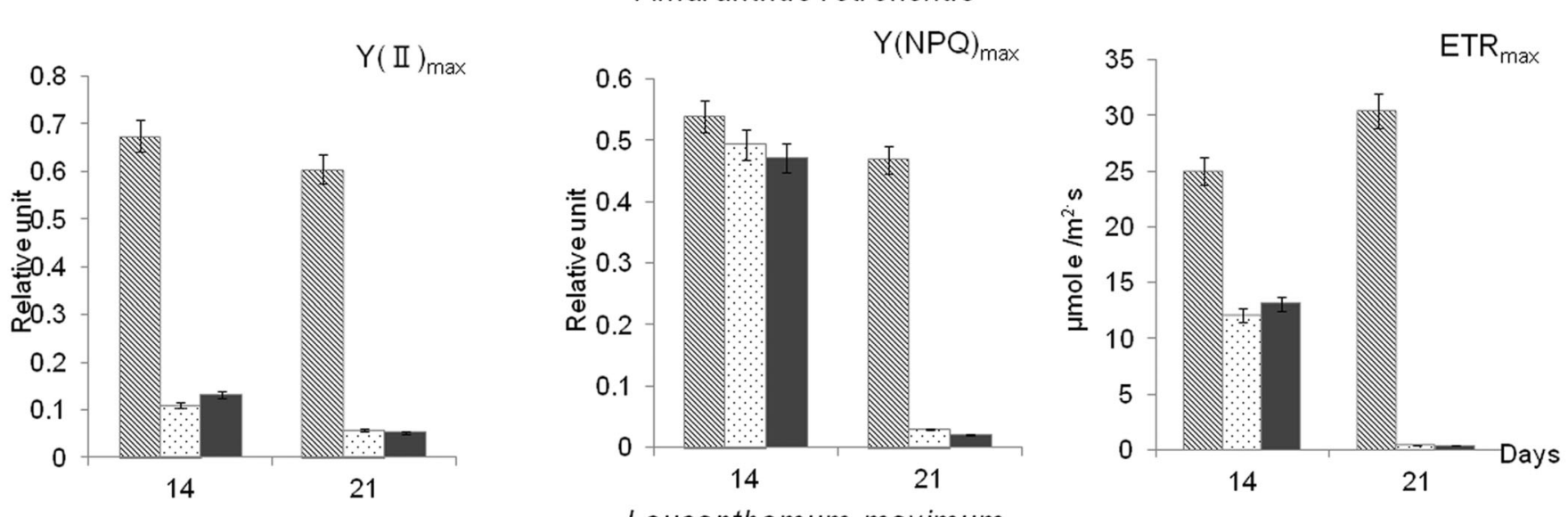

766

767

768

769

770

771

772

773

774

775

776

777

778

779

780

23

724

725

726

727

728

729

730

731

732

734

735

736

737

738

739

740

741

742

743

744

745

746

747

748

749

750

751

752

753

754
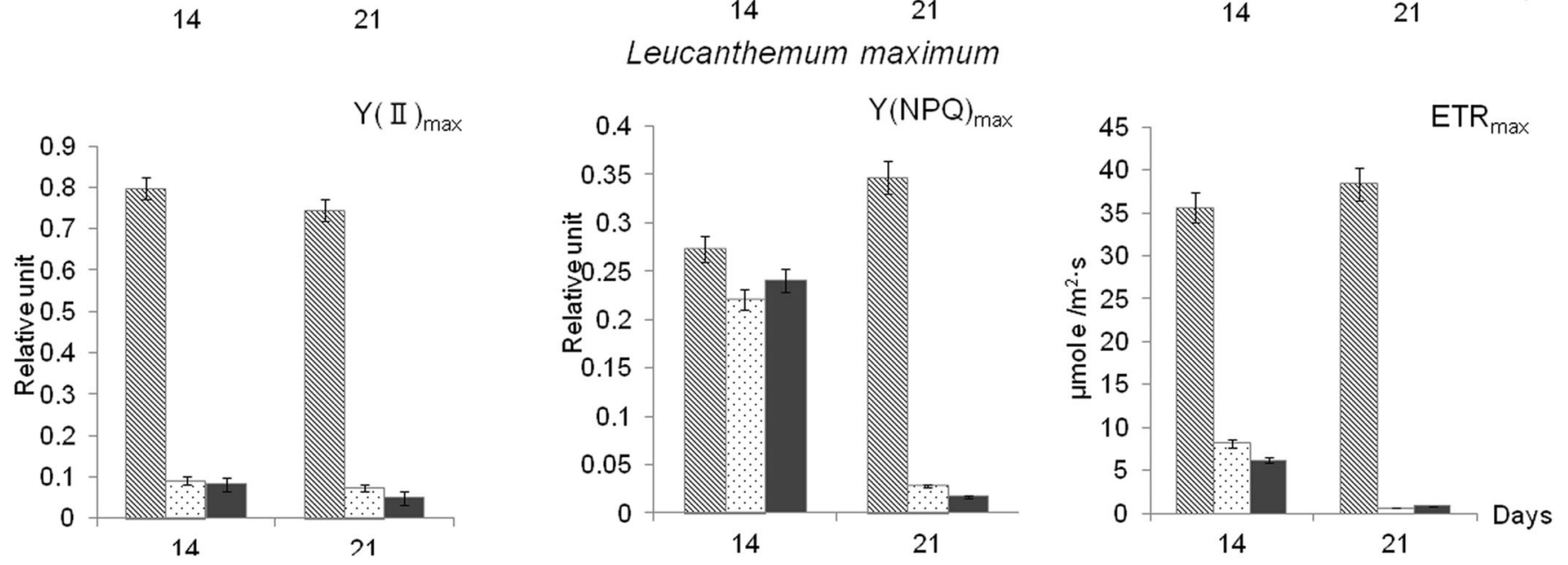

781

782

783

784

785

786

787

788

789

790

791

792

793

794

795

796

797

798

799

800

801

802

803

804

805

806

807

808

\section{$\mathbb{W}$ Control $«-\pi) \therefore \quad \therefore \quad$ Control MET «+» $\quad \mathrm{P}(3 \mathrm{HB}) /$ wood flour/MET}

809

810

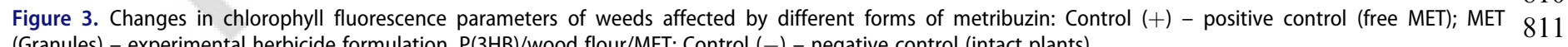
(Granules) - experimental herbicide formulation, $\mathrm{P}(3 \mathrm{HB}) /$ wood flour/MET; Control (-) - negative control (intact plants).

carotenoids, and interrupted protein biosynthesis, blocking electron transport of PSII. ${ }^{[30]}$ Maximum quantum yield decreased when the B. pilosa weed and soybean (Glycine max) were treated with a commercial formulation of atrazine and the herbicide encapsulated in nanocapsules of poly( $\varepsilon$-caprolactone). ${ }^{[31]}$ An ETR decrease was detected after atrazine treatment of maize, weeds, and Calophyllum brasiliense. ${ }^{[32]}$ Application of nanocapsules with atrazine decreased Y(II) and ETR in the Amaranthus viridis and 815 Bidens pilosa weeds. ${ }^{[33]}$

The effect of tribenuron-methyl on photosynthetic activ- 817 ity of weeds is more complex and controversial. Herbicides 818 based on sulfonylurea, containing TBM as the active ingredi- 819 ent, do not directly affect the photosynthesis system but 820 rather impact the function of acetolactate synthase (ALS). 821 The adverse effects of sulfonylureas, inhibiting ALS, such as 822 

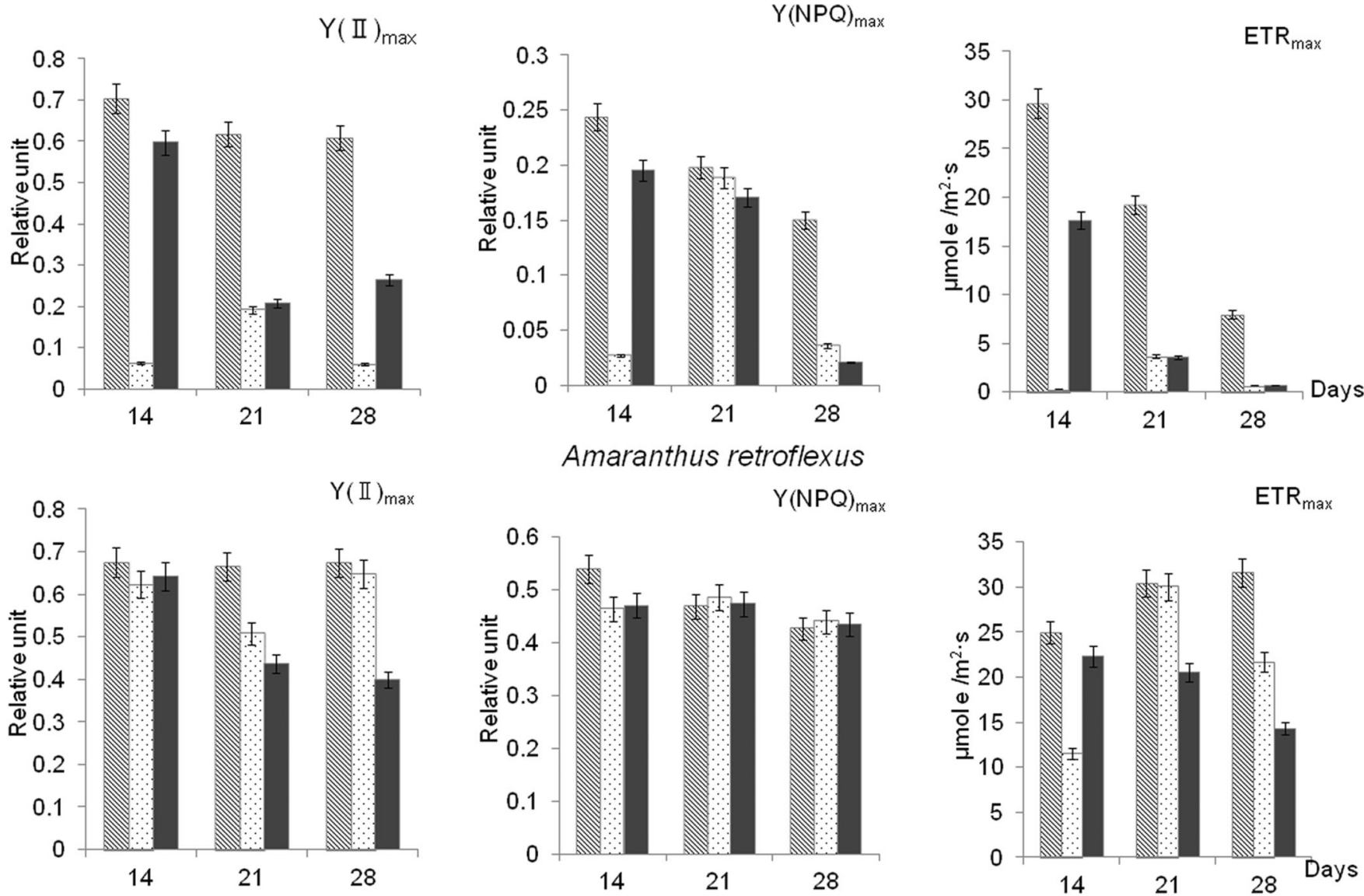

Amaranthus retroflexus
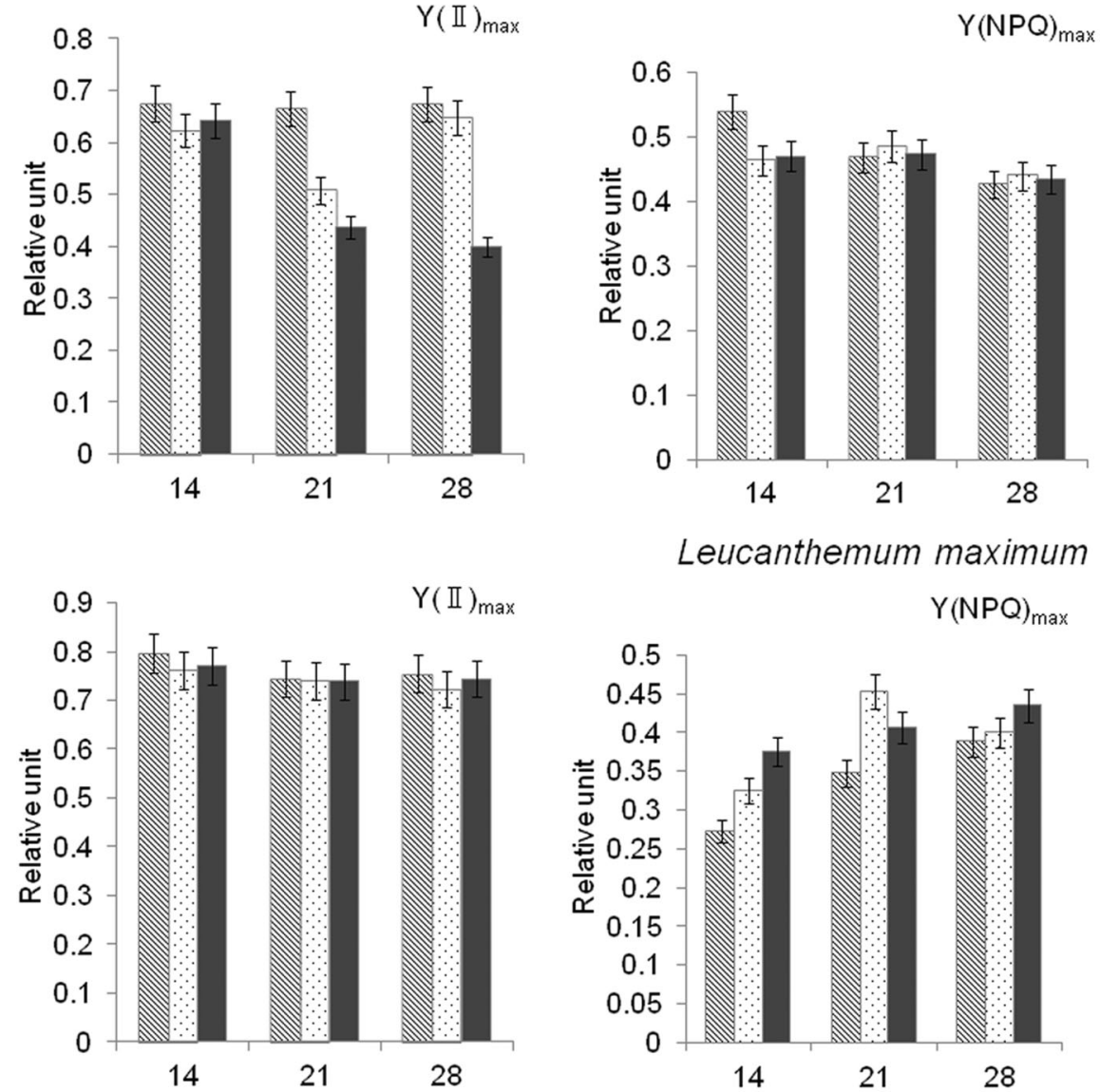

Leucanthemum maximum
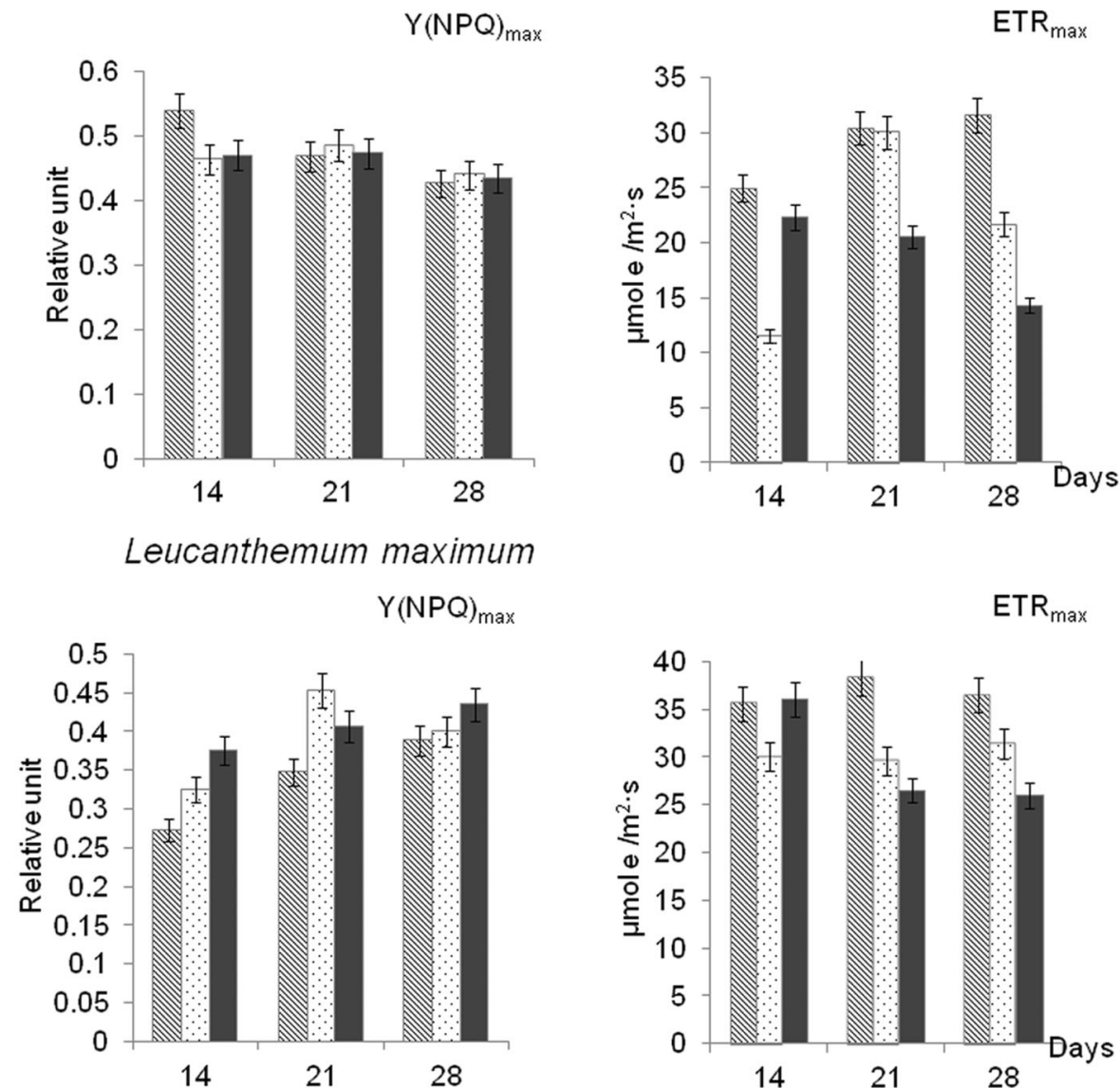

915

916

917

\section{$\mathbb{W}$ Control «-» $\because \because \quad$ Control TBM «+» $\quad$ P $(3 \mathrm{HB}) /$ wood flour/TBM}

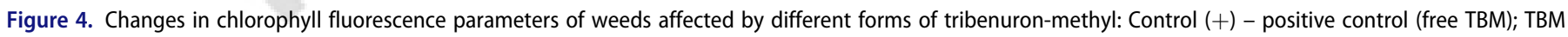
(Granules) - experimental herbicide formulation, $\mathrm{P}(3 \mathrm{HB}) /$ wood flour/TBM; Control $(-)$ - negative control (intact plants).

chlorosis, necrosis, and inhibition of growth of plants were described by Agostinetto et al. ${ }^{[8]}$ Relatively recent research showed that many of the effects produced by ALS inhibiting herbicides were associated with biogenesis of ribosomes, secondary metabolism, cell wall modification, and cell growth. ${ }^{[34,35]}$ For instance, the glyphosate can affect other physiological processes in the plant. ${ }^{[34]}$ Numerous studies demonstrated decreases in the photosynthetic rate of plants following treatment with glyphosate. ${ }^{[36,37]}$ Moreover, glyphosate can indirectly affect photosynthesis by inhibiting chlorophyll biosynthesis or inducing chlorophyll degradation, ${ }^{[38]}$ decreasing stomatal conductance, ${ }^{[39]}$ and provoking nutritional disturbances. ${ }^{[40]}$ Measurements of chlorophyll fluorescence parameters in weeds are shown in Figure 4. Experiments with field mustard and red-root amaranth demonstrated a considerable inhibitory effect of tribenuron- 
Table 3. Changes in photosynthesis pigment contents of weeds treated with the free and embedded metribuzin and tribenuron-methyl.

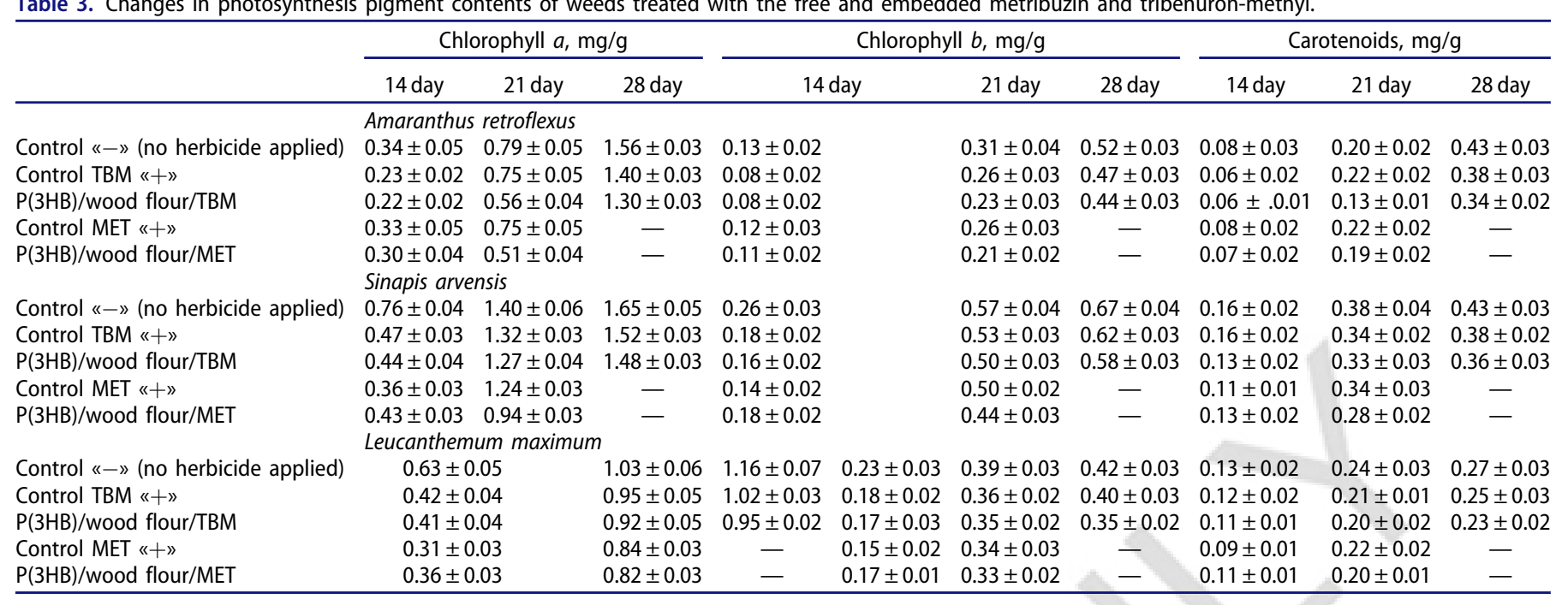

methyl on photosynthesis and a decrease in $\mathrm{Y}(\mathrm{II})_{\max }$ and ETR $_{\max }$. The photoactivity of the field mustard plants was the least stable when affected by tribenuron-methyl: the $\mathrm{Y}(\mathrm{II})_{\max }$ and $\mathrm{Y}(\mathrm{NPQ})_{\max }$ of this plant considerably decreased, in contrast to $\mathrm{ETR}_{\max }$, at day 14 in the positive control (with free TBM). At the same time, $\mathrm{Y}(\mathrm{II})_{\max }$, $\mathrm{Y}(\mathrm{NPQ})_{\max }$, and $\mathrm{ETR}_{\max }$ in experiments with red-root amaranth and max chrysanthemum did not change significantly during the experiment. The reduction in $\mathrm{Y}(\mathrm{II})_{\max }$ suggested substantial damage to the photosynthetic apparatus of redroot amaranth and, especially, field mustard. There are literature data suggesting that in some plants, e.g., in Radix isatidis, TBM causes a decrease in Y(II) and ETR in PSII. ${ }^{[25]}$ Trace concentrations of imazethapyr (ALS inhibitor) caused a dramatic increase in reactive oxygen species (ROS) in A. thaliana. ${ }^{[29]}$

In experiments with max chrysanthemum, TBM considerably decreased $\mathrm{ETR}_{\max }$ and somewhat increased $\mathrm{Y}(\mathrm{NPQ})_{\max }$ relative to the intact plants. TBM did not affect the $\mathrm{Y}(\mathrm{II})_{\max }$ of max chrysanthemum, and it was similar to the control level during the experiment. Similar results (except a decrease in $\mathrm{Y}(\mathrm{NPQ})$ ) were obtained after treating cornflower with tribenuron-methyl: no significant changes were observed in $\mathrm{Y}(\mathrm{II})$ but ETR and $\mathrm{Y}(\mathrm{NPQ})$ decreased. ${ }^{[34]}$

Thus, differences in changes of parameters $\mathrm{Y}(\mathrm{II})_{\max }$, $\mathrm{Y}(\mathrm{NPQ})_{\max }$, and ETR suggest that application of the free TBM causes a pronounced response in most plants in the early phase of the experiment but it usually becomes less intense later. By contrast, the embedded TBM produces a somewhat delayed effect, which becomes stronger by the middle of the experiment and reaches its peak over time.

\section{The effect of herbicides on the contents of photosynthesis pigments}

Another important indicator of plant photosynthetic activity, along with chlorophyll fluorescence parameters, is the state of chlorophyll-protein complexes.
The study of photosynthetic activity of weeds treated 1019 with the free and embedded herbicides included analysis of 1020 changes in chlorophyll $\mathrm{a}, \mathrm{b}$ and carotenoid contents in 1021 chlorophyll-protein complexes. The pigment contents of 1022 different plant species treated with free and embedded 1023 herbicides had similar patterns of change. Regardless of 1024 the herbicide used, its form, and plant species treated, 1025 chlorophyll $a$ and $b$ increased as the plants were growing 1026 and developing, but the pattern of change of carotenoids 1027 was more intricate. However, concentrations of the pig- 1028 ments varied significantly depending on the plant species. 1029 Intact and herbicide-treated plants of two species (Sinapis 1030 arvensis and Leucanthemum maximum) contained almost 1031 twice as high concentrations of the green pigments and 1032 carotenoids compared with Amaranthus retroflexus (Table 1033 3). Changes in the pigment concentrations were compared 1034 in the experiments with herbicides that had different 1035 modes of action (metribuzin and tribenuron-methyl) and 1036 with different forms of the herbicides (free and embedded 1037 ones) (Table 3). Both herbicides caused a decrease in 1038 chlorophyll $a$ and $b$ relative to the intact plants, regardless 1039 of the herbicide form, and the patterns of change were 1040 similar while quantitative changes differed somewhat. The 1041 greatest decrease in chlorophyll $a$ was $53 \%$ and chloro- 1042 phyll $b 46 \%$ in Sinapis arvensis at day 14 in the experi- 1043 ment with the free MET.

In contrast to the green pigments, carotenoid contents of 1045 all weed species were quantitatively similar in the intact and 1046 herbicide-treated plants. As plants developed, carotenoid 1047 contents increased in all species in the experiments with 1048 both free and embedded MET and TBM (Table 3).

Thus, both free and embedded MET and TBM caused a 1050 quantitatively similar decrease in chlorophyll $a$ and $b$ in 1051 various weed species compared to intact plants. The 1052 decrease in concentrations of photosynthesis pigments in 1053 plants treated with herbicides is usually attributed to the 1054 damage to the chlorophyll synthesis system and increased 1055 degradation of pigments, which is also caused by natural 1056 aging of plants. ${ }^{[38]}$ This is consistent with the available lit- 1057 erature data on the effects of some herbicides on plants. For 1058 
example, a study by Qian et al. ${ }^{[29]}$ showed a strong effect of trace concentrations of imazethapyr (an ALS inhibitor) on A. thaliana plants and a decrease in chlorophyll synthesis. Treatment of rape with amidosulfuron (an ALS inhibitor) also resulted in a considerable chlorophyll decrease. ${ }^{[35]}$ Treatment of willow with the glyphosate-based herbicide caused a decrease in chlorophyll concentrations and an increase in carotenoid concentrations at day 7 , followed by a decrease. ${ }^{[41]}$ An increase in carotenoids was observed in Centaurea cyanus L. biotopes treated with tribenuronmethyl. ${ }^{[34]}$ Carotenoids usually take part in protection from oxidative damage by detoxifying oxygen singlets produced by photosynthesis or enzymatic transformation of other ROS into oxygen singlets. ${ }^{[42]}$ The present study suggests that findings obtained in research of photosynthetic activity of plants using chlorophyll fluorescence parameters have high information value.

\section{Conclusion}

The study of the efficacy of the free and embedded forms of metribuzin and tribenuron-methyl in controlling various weeds showed that embedding of the herbicides in degradable matrix did not decrease their activity but prolonged their action and, in some cases, even enhanced their efficacy. Embedded MET, which caused $100 \%$ mortality of the weeds, was found to be the more effective herbicide. The herbicidal activity of the embedded TBM was superior to its activity in the free form: the embedding of this herbicide, which is quickly inactivated and metabolized in plant tissues, enhanced and prolonged its action. The study showed that the herbicides decreased the main parameters of fluorescence $\left[\mathrm{Y}(\mathrm{II})_{\max }, \mathrm{Y}(\mathrm{NPQ})_{\max }\right.$, and $\left.\mathrm{ETR}\right]$ and concentrations of photopigments. Comparison of the free and embedded MET did not reveal any differences between qualitative and quantitative changes in fluorescence parameters of the various plants affected by the two forms. The effect of the embedded TBM was somewhat delayed in the early phase of the experiment but lasted longer than the effect of the free TBM and increased over time.

\section{Funding}

This work was supported by Project "Agropreparations of the new generation: a strategy of construction and realization" [Agreement No 074-02-2018-328] in accordance with Resolution No 220 of the Government of the Russian Federation of April 9, 2010, "On measures designed to attract leading scientists to the Russian institutions of higher learning".

\section{ORCID}

Sergey Baranovsky (D) http://orcid.org/0000-0001-7029-7768 Olga Petrovskaya (D) http://orcid.org/0000-0002-3875-0718

\section{References}

[1] Kumar, S.; Bhanjana, G.; Sharma, A.; Sidhu, M. C.; Dilbaghi, N. Synthesis, Characterization and on Field Evaluation of Pesticide Loaded Sodium Alginate Nanoparticles. Carbohydr. Polym. 2014, 101, 1061-1067. DOI: 10.1016/j.carbpol.2013.10.025.

[2] Volova, T.; Shishatskaya, E.; Prudnikova, S.; Zhila, N.; Boyandin, A. New Generation Formulations of Agrochemicals: Current Trends and Future Priorities; CRC/Taylor\&Francis: Appl. Acad. Press: Toronto, Canada, 2019; p. 286.

[3] Boyandin, A. N.; Zhila, N. O.; Kiselev, E. G.; Volova, T. G. Constructing Slow-Release Formulations of Metribuzin Based on Degradable Poly(3-Hydroxybutyrate). J. Agric. Food Chem. 2016, 64, 5625-5632. DOI: 10.1021/acs.jafc.5b05896.

[4] Volova, T. G.; Zhila, N. O.; Vinogradova, O. N.; Nikolaeva, E. D.; Kiselev, E. G.; Shumilova, A. A.; Shershneva, A. M.; Shishatskaya, E. I. Constructing Herbicide Metribuzin Sustained-Release Formulations Based on the Natural Polymer Poly-3-Hydroxybutyrate as a Degradable Matrix. J. Environ. Sci. Health B. 2016, 51, 113-125. DOI: 10.1080/03601234.2015. 1092833.

[5] Zhila, N.; Murueva, A.; Shershneva, A.; Shishatskaya, E.; Volova, T. Herbicidal Activity of Slow-Release Herbicide Formulations in Wheat Stands Infested by Weeds. J. Environ. Sci. Health B. 2017, 52, 729-735. DOI: 10.1080/03601234.2017. 1356668.

[6] Volova, T.; Prudnikova, S.; Boyandin, A.; Zhila, N.; Kiselev, E.; Shumilova, A.; Baranovsky, S.; Demidenko, A.; Shishatskaya, E.; Thomas, S. Constructing Slow-Release Fungicide Formulations Based on Poly(3-Hydroxybutyrate) and Natural Materials as a Degradable Matrix. J. Agric. Food Chem. 2019, 67, 220-9231. DOI: $10.1021 /$ acs.jafc.9b01634.

[7] Thomas, S.; Shumilova, A. A.; Kiselev, E. G.; Baranovsky, S. V.; Vasiliev, A. D.; Nemtsev, I. V.; Kuzmin, A. P.; Sukovatyi, A. G.; Avinash, R. P.; Volova, T. G. Thermal, Mechanical and Biodegradation Studies of Biofiller Based Poly-3Hydroxybutyrate Biocomposites. Int. J. Biol. Macromol. 2020, 155, 1373-1384. DOI: 10.1016/j.ijbiomac.2019.11.112.

[8] Agostinetto, D.; Perboni, L. T.; Langaro, A. C.; Gomes, J.; Fraga, D. S.; Franco, J. J. Changes in Photosynthesis and Oxidative Stress in Wheat Plants Submmited to Herbicides Application. Planta Daninha. 2016, 34, 1-9. DOI: 10.1590/ S0100-83582016340100001.

[9] Sun, L.; Xu, H.; Hao, H.; An, S.; Lu, C.; Wu, R.; Su, W. Effects of Bensulfuron-Methyl Residue on Photosynthesis and Chlorophyll Fluorescence in Leaves of Cucumber Seedlings. PLoS One 2019, 14, e0215486. DOI: 10.1371/journal.pone. 0215486.

[10] Gomes, M. P.; Le Manac'h, S. G.; Hénault-Ethier, L.; Labrecque, M.; Lucotte, M.; Juneau, P. Glyphosate-Dependent Inhibition of Photosynthesis in Willow. Front. Plant. Sci. 2017, 8, 207-213. DOI: $10.3389 /$ fpls.2017.00207.

[11] Rakitsky, V. N. Handbook of Pesticides (Toxicological-Hygienic Characterization), 4th ed.; Agrorus- Publishers: Moscow, 2011. (in Russian).

[12] Abbott, W. S. A Method of Computing the Effectiveness of an Insecticide. J. Econ. Entomol. 1925, 18, 265-267. DOI: 10.1093/ jee/18.2.265a.

[13] Lichtenthaler, H. K.; Buschmann, C. Chlorophylls and Carotenoids: Measurement and Characterization by UV-VIS Spectroscopy. Curr. Protocol Food Anal. Chem. 2001, 1, F4.3.1-F4.3.8. DOI: 10.1002/0471142913.faf0403s01.

[14] Alebrahim, M. T.; Majd, R.; Rashed Mohassel, M. H.; Wilcockson, S.; Baghestani, M. A.; Ghorbani, R.; Kudsk, P. Evaluating the Efficacy of Pre- and Post-Emergence Herbicides for Controlling Amaranthus retroflexus L. and Chenopodium album L. in Potato. Crop Protect. 2012, 42, 345-350. DOI: 10. 1016/j.cropro.2012.06.004.

[15] Tagour, M. H. R.; Mosaad, I. S. M. Effect of the Foliar Enrichment and Herbicides on Maize and Associated Weeds 
[20] Chamanabad, H. A. M.; Zand, H. R.; Biabani, E.; Asghari, A. Ecological Fitness of Tribenuron Methyl (Als-Inhibitor Herbicide) Susceptible and Resistant Biotypes of Wild Mustard in Competition with Wheat. Appl. Ecol. Env. Res. 2019, 17, 6227-6240. DOI: 10.15666/aeer/1703_62276240.

[21] Qi, Y.; Li, J.; Fu, G.; Zhao, C.; Guan, X.; Yan, B.; Ren, M. Effects of Sublethal Herbicides on Offspring Germination and Seedling Growth: Redroot Pigweed (Amaranthus Retroflexus) vs. velvetleaf (Abutilon Theophrasti). Sci. Total Environ. 2018, 645, 543-549. DOI: 10.1016/j.scitotenv.2018.07.171.

[22] Kumar, S.; Bhanjana, G.; Sharma, A.; Dilbaghi, N.; Sidhu, M. C.; Kim, K. H. Development of Nanoformulation Approaches for the Control of Weeds. Sci. Total Environ. 2017, 586, 1272-1278. DOI: 10.1016/j.scitotenv.2017.02.138.

[23] Vieira, B. C.; Luck, J. D.; Amundsen, K. L.; Gaines, T. A.; Werle, R.; Kruger, G. R. Response of Amaranthus spp. following Exposure to Sublethal Herbicide Rates via Spray Particle Drif. PLoS One 2019, 14, e0220014. DOI: 10.1371/journal.pone. 0220014

[24] Gil, S. S.; Tuteja, N. Reactive Oxygen Species and Antioxidant Machinery in Abiotic Stress Tolerance in Crop Plants. Plant Physiol. Biochem. 2010, 48, 909-930. DOI: 10.1016/j.plaphy. 2010.08.016.

[25] Foyer, C. H.; Noctor, G. Ascorbate and Glutathione: The Heart of the Redox Hub. Plant Physiol. 2011, 155, 2-18. DOI: 10. 1104/pp.110.167569

[26] Demmig-Adams, B.; Garab, G.; William, A., Govindgee (Eds), Non-Photochemical Quenching and Energy Dissipation in Plants, Algae and Cyanobacteria. In: Advances in Photosynthesis, and Respiration Series; Sharkey, T. D.; EatonRye, J., Eds.; Springer Science + Business Media: Dordrecht, the Netherlands, 2014, pp. 471-494.

[27] Formaggio, E.; Cinque, G.; Bassi, R. Functional Architecture of the Major Light-Harvesting Complex from Higher Plants. J. Mol. Biol. 2001, 314, 1157-1166. DOI: 10.1006/jmbi.2000.5179.

[28] Duffy, C. D. P.; Ruban, A. V. Dissipative Pathways in the photosystem-II Antenna in Plants. J. Photochem. Photobiol. B, Biol. 2015, 152, 215-226. DOI: 10.1016/j.jphotobiol.2015.09.011.

[29] Qian, H.; Li, Y.; Sun, C.; Lavoie, M.; Xie, J.; Bai, X.; Fu, Z. Trace Concentrations of Imazethapyr (IM) Affect Floral Organs Development and Reproduction in Arabidopsis thaliana: IMInduced Inhibition of Key Genes Regulating Anther and Pollen
Biosynthesis. Ecotoxicology 2015, 24, 163-171. DOI: 10.1007/ 1236 s10646-014-1369-5.

[30] Frankart, C.; Eullaffroy, P.; Vernet, G. Comparative Effects of 1238 Four Herbicides on Non-Photochemical Fluorescence 1239 Quenching in Lemna minor. Environ. Exp. Bot 2003, 49, 1239
159-168. DOI: 10.1016/S0098-8472(02)00067-9.

[31] Preisler, A. C.; Pereira, A. E.; Campos, E. V.; Dalazen, G.; 1241 Fraceto, L. F.; Oliveira, H. C. Atrazine Nanoencapsulation 1242 Improves Pre-Emergence Herbicidal Activity Against Bidens pilosa without Enhancing Long-Term Residual Effect on 1243 Glycine max. Pest Manag. Sci. 2020, 76, 141-149. DOI: 10. 1244 1002/ps.5482.

[32] Araldi, R.; Corniani, N.; Tropaldi, L.; Girotto, M.; Belapart, D.; 1246 Simoes, P. S.; Velini, E. D. Chlorophyll Fluorescence in 1247 Guanandi Tree (Calophyllum brasiliense) after Herbicide 1248 Application. Planta Daninha. 2015, 33, 77-82. DOI: 10.1590/ S0100-83582015000100009.

[33] Sousa, G. F. M.; Gomes, D. G.; Campos, E. V. R.; de Oliveira, 1250 J. L.; Fraceto, L. F.; Stolf-Moreira, R.; Oliveira, H. C. Post- 1251 Emergence Herbicidal Activity of Nanoatrazine against 1252 Susceptible Weeds. Front Environ. Sci. 2018, 6, 1-6.

[34] Saja, D.; Rys, M.; Stawoska, I.; Skoczowski, A. Metabolic 1253 Response of Cornflower (Centaurea cyanus L.) Exposed to 1254 Tribenuron-Methyl: One of the Active Substances of 1255 Sulfonylurea Herbicides. Acta Physiol. Plan. 2016, 38, 168. DOI: 1256 10.1007/s11738-016-2183-x.

[35] Liu, X. Q.; Yu, C. Y.; Dong, J. G.; Hu, S. W.; Xu, A. X 1257 Acetoacetate Synthase-Inhibiting Gametocide Amidosulfuron 1258 Causes Chloroplast Destruction, Tissue Autophagy, and 1259 Elevation of Ethylene Release in Rapeseed. Front. Plant. Sci. 1260 2017, 8, 1-20. DOI: 10.3389/fpls.2017.01625.

[36] Zobiole, L. H. S.; Kremer, R. J.; Oliveira, R. S., Jr.; Constantin, 1262 J. Glyphosate Effects on Photosynthesis, Nutrient 1263 Accumulation, and Nodulation in Glyphosate-Resistant 1263 Soybean. Z Pflanzenernähr. Bodenk. 2012, 175, 319-330. DOI: 1264 10.1002/jpln.201000434.

[37] Diaz Vivancos, P.; Driscoll, S. P.; Bulman, C. A.; Ying, L.; 1266 Emami, K.; Treumann, A.; Mauve, C.; Noctor, G.; Foyer, C. H. 1267 Perturbations of Amino Acid Metabolism Associated with 1268 Glyphosate-Dependent Inhibition of Shikimic Acid Metabolism 1268 Affect Cellular Redox Homeostasis and Alter the Abundance of 1269 Proteins Involved in Photosynthesis and Photorespiration. Plant 1270 Physiol. 2011, 157, 256-268. DOI: 10.1104/pp.111.181024.

[38] Gomes, M. P.; Le Manac'h, S. G.; Maccario, S.; Labrecque, M.; 1272 Lucotte, M.; Juneau, P. Differential Effects of Glyphosate and 1273 Aminomethylphosphonic Acid (AMPA) on Photosynthesis and 1273
Chlorophyll Metabolism in Willow Plants. Pestic. Biochem. 1274 Physiol. 2016, 130, 65-70. DOI: 10.1016/j.pestbp.2015.11.010. 1275

[39] Yanniccari, M.; Tambussi, E.; Istilart, C.; Castro, A. M. 1276 Glyphosate Effects on Gas Exchange and Chlorophyll 1277 Fluorescence Responses of Two Lolium perenne L. biotypes 1278 with Differential Herbicide Sensitivity. Plant Physiol. Biochem. 2012, 57, 210-217. DOI: 10.1016/j.plaphy.2012.05.027.

[40] Su, Y. S.; Ozturk, L.; Cakmak, I.; Budak, H. Turfgrass Species 1280 Response Exposed to Increasing Rates of Glyphosate 1281 Application. Eur. J. Agron 2009, 31, 120-125. DOI: 10.1016/j. 1282 eja.2009.05.011.

[41] Gomes, M. P.; Smedbol, E.; Carneiro, M. M. L. C.; Garcia, 1283 Q. S.; Juneau, P. Reactive Oxygen Species and Plant Hormones. 1284 In P. Ahmad (Ed.), Oxidative Damage to Plants: Antioxidant 1285 Networks and Signaling; Academic Press: San Diego, CA, 2014, 1286 pp. $65-88$

[42] Boussiba, S. Carotenogenesis in the Green Alga Haematococcus 1287 pluvialis: Cellular Physiology and Stress Response. Physiol. Plant. 2000, 108, 111-117. DOI: $10.1034 / j .1399-3054.2000$. 108002111. 